\title{
Attitudes toward anticoagulant treatment among nonvalvular atrial fibrillation patients at high risk of stroke and low risk of bleed
}

This article was published in the following Dove Press journal:

Patient Preference and Adherence

17 May 2016

Number of times this article has been viewed

\section{Concetta Crivera' \\ Winnie W Nelson' \\ Jeff R Schein' \\ Edward A Witt ${ }^{2}$}

'Janssen Scientific Affairs, LLC, Raritan, ${ }^{2}$ Kantar Health, Princeton, NJ, USA

Correspondence: Edward A Witt Kantar Health, I Independence Way, Suite \#220, Princeton, NJ 08540, USA Tel + I 609720 549|

Email edward.witt@kantarhealth.com
Background: Atrial fibrillation (AF) is associated with an increased risk of stroke. Anticoagulant (AC) therapies are effective at treating $\mathrm{AF}$, but carry with them an increased risk of bleed. Research suggests that a large proportion of AF patients who have high risk of stroke and low risk of bleeding are not currently receiving AC treatment. The goal of this study was to understand the reasons why these patients do not engage in this potentially life-saving treatment.

Method: Through a self-report online survey, using validated instruments, 1,184 US adults who self-reported a diagnosis of AF were screened for the risk of stroke and bleed. Of these patients, 230 (19.4\%) were at high risk of stroke, low risk of bleed, and not currently using an AC treatment, and were asked follow-up questions to assess their reasons for nontreatment, attitudes toward treatment, and attitudes toward dosing regimens.

Results: The most common reasons patients stopped AC treatment were concerns regarding bleeding (27.8\%) and other medical concerns (26.6\%), whereas the most common reason cited for not being prescribed an $\mathrm{AC}$ in the first place was the use of antiplatelet therapy as an alternative $(57.1 \%)$. In both cases, potentially erroneous decisions regarding perceived stoke and/or bleeding risk were also a factor. Finally, the largest factors regarding attitudes toward treatment and dosing regimen were instructions from an authority figure (eg, physician, pharmacist) and ease of use, respectively.

Conclusion: Results suggest that many AF patients who are at high risk of stroke but at low risk of bleed may not be receiving $\mathrm{AC}$ due to potentially inaccurate beliefs about risk. This study also found that AF patients place trust in physicians above other factors such as cost when making treatment decisions. Increased education of patients by physicians on the risks and benefits may be a simple strategy to improve outcomes.

Keywords: atrial fibrillation, anticoagulants, stroke risk, bleeding risk, treatment

\section{Introduction}

Atrial fibrillation (AF) is a supraventricular tachyarrhythmia with uncoordinated atrial activation and consequently ineffective atrial contraction. ${ }^{1-3} \mathrm{AF}$ is the most common sustained cardiac arrhythmia and is associated with substantial morbidity and mortality. ${ }^{4} \mathrm{AF}$ is independently associated with an increased risk of stroke, thromboembolism, dementia, and congestive heart failure..$^{5-7}$ Nearly 500,000 hospitalizations list AF as the primary diagnosis annually in the US, and AF is estimated to contribute to nearly 100,000 deaths per year. ${ }^{8,9}$

According to recently updated clinical guidelines, AF patients should generally receive an anticoagulant (AC) or antiplatelet (ie, aspirin [ASA]) regimen depending on their degree of risk for stroke and serious bleeding. ${ }^{1,2,10,11}$ Risk scores (eg, $\mathrm{CHADS}_{2}$, 
$\mathrm{CHA}_{2} \mathrm{DS}_{2}-\mathrm{VASc}$, and HAS-BLED) $)^{12,13}$ have been developed to inform physicians about which patients have the greatest need for treatment and which treatment(s) to use. ${ }^{11}$ The 2014 updated guidelines recommend oral $\mathrm{AC}$ in patients with a $\mathrm{CHA}_{2} \mathrm{DS}_{2}-\mathrm{VASc} \geq 2$, optional ASA in patients with a score of 1 , and no treatment for patients with a score of 0 .

Despite the availability of these risk algorithms, research suggests that a substantial gap exists between patient risk status and their receiving the appropriate treatment. ${ }^{14,15}$ Therefore, AF patients at heightened risk for morbidity may not be receiving the recommended treatment - even when they are at low risk for medication side effects (eg, serious bleeding). Indeed, research shows AC medications to be underutilized in AF patients at high risk for stroke, despite the potential for high gain with low risk in many individuals. Moreover, although this problem has been identified, the specific reasons for lack of treatment have not been explored. ${ }^{14,16,17}$

\section{Present study}

Although AC medications are recommended for patients with a $\mathrm{CHA}_{2} \mathrm{DS}_{2}-\mathrm{VASc} \geq 2$, the newest 2014 guidelines do not endorse any single AC as the most preferred. Rather, they advocate patient-centered decision making (ie, patient values and preferences) as the top-line Class I recommendation. Understanding the highly complex confluence of appropriate medication regimen availability with patient attitudes toward medication is, therefore, also imperative. ${ }^{3}$

Given the notable updates in clinical guidelines for prevention of AF-related morbidity, research is needed to elucidate the characteristics of specific patient groups who are not receiving treatment and to understand the reasons for nontreatment. Doing so may lay a foundation for preventing unnecessary morbidity. This study attempted to quantify patients' reasons for nontreatment and attitudes toward medication use in a sample of nonvalvular atrial fibrillation (NVAF) patients at high risk of stroke and low risk of bleed, who were not currently using an AC.

\section{Methods}

\section{Sample}

Respondents were recruited through Lightspeed Research and their panel partners. Lightspeed Research is an opt-in consumer panel where participants are asked to participate in a series of questionnaires in exchange for "panel points" that are credited to the panelist's account after participation and can be used for products, online gift certificates, or a cash honorarium. Lightspeed maintains an active database of panelists and uses several methodologies to recruit panelists (eg, email, co-registration, e-newsletter campaigns) in an effort to reduce bias due to too few sources. All participation is voluntary. Lightspeed goes through extensive efforts at both the panel and data collection phases to ensure data quality including verifying participants' identities and detecting dishonest and inconsistent responding.

Potential respondents were invited to participate in the current study through email. After clicking on the email link and giving informed consent, potential participants were presented with a series of screening questions that included questions about NVAF status, risk of stroke $\left(\mathrm{CHA}_{2} \mathrm{DS}_{2}-\mathrm{VASc}\right),{ }^{13}$ risk of bleed (ATRIA), ${ }^{18}$ and current AC treatment status. The $\mathrm{CHA}_{2} \mathrm{DS}_{2}-\mathrm{VASc}$ and ATRIA are risk scores calculated from a series of health (eg, diagnoses) and demographic (eg, age, sex) questions. In this study, a score of $\geq 2$ on the $\mathrm{CHA}_{2} \mathrm{DS}_{2}$-VASc qualified a participant as "high risk" for stroke; whereas a score of 0-3 on the ATRIA qualified a participant as "low risk" for bleeding. Among those screened, those who had NVAF, high risk for stroke (according to the $\mathrm{CHA}_{2} \mathrm{DS}_{2}-\mathrm{VASc}$ ), low risk for bleed (according to the ATRIA), and who were not currently treating their NVAF with AC therapy completed the main survey questionnaire. In addition to these stipulations, all participants were required to be over 18 years of age, provide informed consent, not have a diagnosis of mitral stenosis, and not have a mechanical heart valve in order to be eligible to participate. This study was reviewed and approved by the Sterling Institutional Review Board.

\section{Patient characteristics}

\section{Demographics and health characteristics}

All participants were asked to self-report the following demographic variables: sex, year of birth, and race. These demographics were used both descriptively and to create strata (age $\times$ sex) for the purposes of weighting. A series of additional demographic questions were given to only those patients who completed the main questionnaire. These included: marital status, education, employment, income, smoking status, alcohol status, exercise status, and height and weight (for body mass index calculation).

\section{Frailty}

Patient frailty was assessed using two questions. Specifically, if a patient responded that he or she used any medical assistance device (ie, wheelchair, walker, cane, commode chair, or home oxygen therapy) and/or he or she reported any of the following, that is, hip fracture, chronic kidney disease, or dialysis, he or she was categorized as "frail". 


\section{Measures}

\section{Reasons for stopping taking an AC (asked of previous AC users)}

Previous AC users were asked, "Which of the following are reasons why you stopped taking an anticoagulant to treat your atrial fibrillation?" and were told to select all that were applicable from a list of 22 reasons for stopping an AC presented in a randomized order. These reasons were grouped into the following factors based on item content: cost (four items; eg, "I could not afford the prescription medication"), patient beliefs and preferences (three items; eg, "I do not believe I am at high risk of stroke"), self-efficacy (five items; eg, "I had concerns about following the medication instructions"), medical (five items; eg, "I injured myself and my doctor told me to stop taking an anticoagulant"), and bleeding concern (five items; eg, "I had concerns about the risk of bleeding [internally or because of injuries]"). The full list is available in Figure S1.

\section{Reasons for never starting AC therapy (asked of those who were prescribed an AC but did not fill the prescription)}

Patients who indicated that they had previously been prescribed an AC but did not fill the prescription were asked, "Why did you not fill the anticoagulant prescription your physician recommended?" and were told to select all that were applicable from a list of 22 reasons (in a randomized order). Example items included "I had concerns about following the medications instructions" and "I could not afford the prescription medication". The full list is available in Figure S2.

\section{Reasons for never being prescribed AC therapy (asked of those who were never prescribed AC)}

Patients who had never been prescribed an AC were asked, "Why weren't you prescribed an anticoagulant (eg, warfarin) to treat your atrial fibrillation?" and were told to select all that were applicable from a list of nine reasons (in a randomized order). These reasons were grouped into the following factors based on item content: physician order (two items; eg, "Due to my risk for injuries from activities [social or job related], my doctor suggested that I not treat my AF with an anticoagulant"), stroke risk (two items; eg, "I believe that I do not have high risk of stroke"), antiplatelets (three items; eg, "I prefer to just take aspirin"), and other (two items; "I was diagnosed at an ER and was not given any prescriptions to fill/to take following my discharge"). The full list is available in Figure S3.

\section{Patient preferences}

All patients who completed the main questionnaire were asked to indicate their agreement with eleven statements (presented in random order) concerning AF treatment with the stem, "Please read each of the following statements and indicate on the scale below how much you agree with each statement". Patients then responded to each item using a seven-point Likert scale (1= "strongly disagree", 7="strongly agree"). The statements were grouped into the following factors based on item content: authority (four items; "I'm willing to take an additional medication if my doctor says I need it to prevent heart attack or stroke"), cost concerns/ patient preference (four items; "I prefer that my health care provider prescribes me the least expensive drugs for me"), and medication cautiousness (three items; "It is more important to me for a medication to have fewer or no side effects, even if my doctor says it is less effective"). The full list of statements is available in Figure S4.

\section{Willingness to adhere to complex dosing regimens}

All patients who completed the main questionnaire were also asked to indicate their willingness to adhere to six different hypothetical dosing regimens (presented in random order) with the stem, "Below is a list of statements related to the treatment of your atrial fibrillation. On the scale below, please indicate your level of willingness to take each prescribed treatment". Patients then responded to each item using a five-point Likert scale (1= "not at all willing", $5=$ "extremely willing"). These items were: "Taking a pill once a day with a meal, such as dinner", "Taking a pill twice a day with or without a meal", "Taking a pill that may require dosage changes often", "Taking a pill that requires frequent follow-up visits (at least once a month to a doctor)", "Taking a medication that requires I avoid eating certain foods (such as leafy greens and certain fruits)", and "Taking a medication that requires routine monitoring with blood tests once a month". Patient dosing regimen characteristics are available in Figure S5.

\section{Analyses}

Demographic data were used to construct weights based on estimates for the adult AF population using data from Naccarelli et al. ${ }^{19}$ Weights were constructed based on the joint strata of age and sex using inverse probability weighting. In this report, only the demographic data presented are weighted, all other estimates presented are unweighted.

This study was primarily descriptive in nature and, as such, reports mean and standard deviation (SD) for 
continuous variables (eg, age) and frequencies and percentages for categorical variables (eg, sex).

\section{Results}

\section{Prevalence of high risk of stroke/low risk of bleed among NVAF patients}

The goal of this study was to recruit a large sample of NVAF patients in order to obtain accurate prevalence estimates of the risk of stroke and the risk of bleed. To accomplish this goal, 33,579 panelists were sent invites to complete the screener. A total of 1,184 US adults (3.5\% of those invited) with AF who met the study inclusion criteria completed the study. Patients were screened for the risk of stroke and the risk of bleed by the $\mathrm{CHA}_{2} \mathrm{DS}_{2}-\mathrm{VASc}$ and ATRIA, respectively (for a description of scoring scheme, see the "Measures" section). In total, $906(76.5 \%)$ of the total sample were classified as "high risk" of stroke according to the $\mathrm{CHA}_{2} \mathrm{DS}_{2}-\mathrm{VASc}$ and $1,081(91.3 \%)$ of the total sample were classified as "low risk" of bleed according to the ATRIA. When combined, a total of $804(67.9 \%)$ qualified as high risk of stroke and low risk of bleed. Of these patients, 230 (19.4\% of total, $28.6 \%$ of high risk stroke/low risk bleed) indicated that they were either never prescribed an $\mathrm{AC}(\mathrm{n}=151,12.8 \%$ of total, $18.8 \%$ of high risk stroke/low risk bleed) or were previously prescribed an AC but were not currently using one $(n=79,6.7 \%$ of total, $9.8 \%$ of high risk stroke/low risk bleed); (Figure 1).

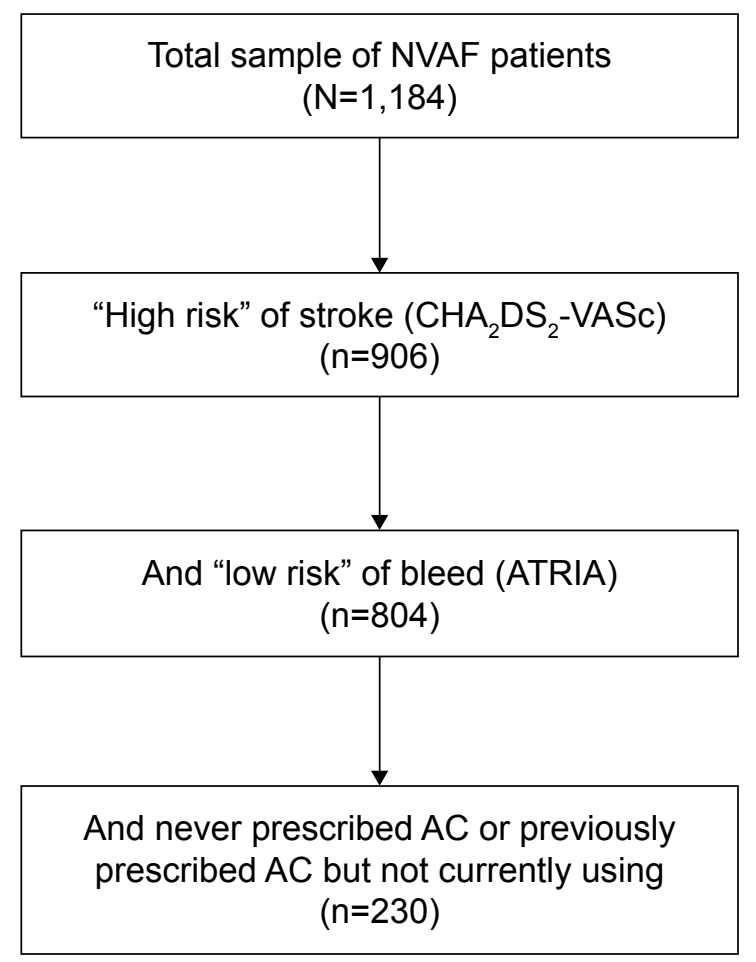

Figure I Study sample selection.

Abbreviations: AC, anticoagulant; NVAF, nonvalvular atrial fibrillation.
When these estimates were weighted to the US adult AF population $(\mathrm{N}=3,033,901)$, they suggest that approximately $87.1 \%$ of US AF patients $(2,649,745)$ are at high risk of stroke, $89.7 \%(2,728,564)$ are at low risk of bleed, and $76.9 \%$ $(2,339,419)$ are at high risk of stroke and low risk of bleed. When considering weighted estimates for current $\mathrm{AC}$ use among this latter group, results suggest that approximately $18.3 \%$ or some 556,493 US adult AF patients are estimated to have never been prescribed an $\mathrm{AC}$ or to have been previously prescribed an AC but not currently using one.

Descriptive statistics characterizing this group are provided in Table 1. In general, this group of patients had an

Table I Descriptive statistics for high-risk stroke/low-risk bleed patients who are not currently using an anticoagulant or have never used an anticoagulant

\begin{tabular}{|c|c|c|c|c|}
\hline \multirow[t]{2}{*}{ Participant characteristics } & \multicolumn{2}{|c|}{$\begin{array}{l}\text { Unweighted } \\
(n=230)\end{array}$} & \multicolumn{2}{|c|}{$\begin{array}{l}\text { Projected } \\
(n=556,493)\end{array}$} \\
\hline & $n / M$ & $\% / S D$ & $n / M$ & $\% / S D$ \\
\hline Age (years) ( $M$ and SD) & 67.17 & 9.63 & 74.83 & 10.24 \\
\hline \multicolumn{5}{|l|}{ Age (years), $n$ and $\%$} \\
\hline $20-54$ & 23 & 10.0 & 25,123 & 4.5 \\
\hline $55-59$ & 17 & 7.4 & 21,107 & 3.8 \\
\hline $60-64$ & 29 & 12.6 & 29,982 & 5.4 \\
\hline $65-69$ & 66 & 28.7 & 69,958 & 12.6 \\
\hline $70-74$ & 49 & 21.3 & 94,072 & 16.9 \\
\hline $75-79$ & 28 & 12.2 & 106,165 & 19.1 \\
\hline $80-84$ & 13 & 5.7 & 76,899 & 13.8 \\
\hline$\geq 85$ & 5 & 2.2 & 133,187 & 23.9 \\
\hline \multicolumn{5}{|l|}{ Sex, $\mathrm{n}$ and $\%$} \\
\hline Male & 102 & 44.3 & 196,975 & 35.4 \\
\hline Female & 128 & 55.7 & 359,518 & 64.6 \\
\hline \multicolumn{5}{|l|}{ Race/ethnicity, $\mathrm{n}$ and \% } \\
\hline White & 219 & 95.2 & 541,859 & 97.4 \\
\hline Black & 8 & 3.5 & 7,807 & 1.4 \\
\hline Other & 3 & 1.3 & 6,828 & 1.2 \\
\hline \multicolumn{5}{|l|}{ Marital status, $\mathrm{n}$ and $\%$} \\
\hline Married & 144 & 62.6 & 307,301 & 55.2 \\
\hline Single, never married & 17 & 7.4 & 27,122 & 4.9 \\
\hline Divorced & 32 & 13.9 & 76,204 & 13.7 \\
\hline Separated & 2 & 0.9 & 2,078 & 0.4 \\
\hline Widowed & 25 & 10.9 & $|3|, 542$ & 23.6 \\
\hline Living with partner & 10 & 4.3 & 12,246 & 2.2 \\
\hline \multicolumn{5}{|l|}{ Education, $n$ and $\%$} \\
\hline Less than high school & 2 & 0.9 & 3,322 & 0.6 \\
\hline High school & 40 & 17.4 & 84,298 & 15.1 \\
\hline Some college & 70 & 30.4 & $152,7 \mid 5$ & 27.4 \\
\hline College degree & 58 & 25.2 & 132,399 & 23.8 \\
\hline Some graduate school & 16 & 7.0 & 62,940 & 11.3 \\
\hline Graduate degree & 44 & 19.1 & 120,820 & 21.7 \\
\hline \multicolumn{5}{|l|}{ Household income, $n$ and \% } \\
\hline$<\$ 15 k$ & 19 & 8.3 & 31,125 & 5.6 \\
\hline$\$ 15 \mathrm{k}$ to $<\$ 25 \mathrm{k}$ & 35 & 15.2 & 89,785 & 16.1 \\
\hline$\$ 25 k$ to $<\$ 35 k$ & 27 & 11.7 & 84,423 & 15.2 \\
\hline$\$ 35 k$ to $<\$ 50 k$ & 32 & 13.9 & 80,903 & 14.5 \\
\hline
\end{tabular}


Table I (Continued)

\begin{tabular}{|c|c|c|c|c|}
\hline \multirow[t]{2}{*}{ Participant characteristics } & \multicolumn{2}{|c|}{$\begin{array}{l}\text { Unweighted } \\
(n=230)\end{array}$} & \multicolumn{2}{|c|}{$\begin{array}{l}\text { Projected } \\
(n=556,493)\end{array}$} \\
\hline & $n / M$ & $\% / S D$ & $n / M$ & $\% / S D$ \\
\hline$\$ 50 \mathrm{k}$ to $<\$ 75 \mathrm{k}$ & 37 & 16.1 & 67,814 & 12.2 \\
\hline$\$ 75 \mathrm{k}$ to $<\$ 100 \mathrm{k}$ & 32 & 13.9 & 45,777 & 8.2 \\
\hline$\$ 100 k$ to $<\$ 125 k$ & 12 & 5.2 & 21,719 & 3.9 \\
\hline$\$ 125 \mathrm{k}$ to $<\$ 150 \mathrm{k}$ & 6 & 2.6 & 43,482 & 7.8 \\
\hline$\$ 150 \mathrm{k}+$ & 10 & 4.3 & 20,930 & 3.8 \\
\hline Declined to answer & 20 & 8.7 & 70,536 & 12.7 \\
\hline \multicolumn{5}{|l|}{ BMI, $\mathrm{n}$ and $\%$} \\
\hline Underweight $(<18.5)$ & I & 0.4 & 2,770 & 0.5 \\
\hline Normal $(18.5$ to $<25)$ & 44 & 19.1 & $|57,08|$ & 28.2 \\
\hline Overweight ( 25 to $<30)$ & 72 & 31.3 & 152,163 & 27.3 \\
\hline Obese $(\geq 30)$ & 103 & 44.8 & 224,522 & 40.3 \\
\hline Declined to answer & 10 & 4.3 & 19,956 & 3.6 \\
\hline \multicolumn{5}{|l|}{ Smoking status, $\mathrm{n}$ and $\%$} \\
\hline Yes, I smoke & 16 & 7.0 & 16,523 & 3.0 \\
\hline Yes, but I am trying to quit & 9 & 3.9 & 12,707 & 2.3 \\
\hline No, I quit smoking & 88 & 38.3 & 223,935 & 40.2 \\
\hline No, I never smoked cigarettes & 117 & 50.9 & 30,328 & 54.5 \\
\hline \multicolumn{5}{|c|}{ How often do you drink alcohol?, $\mathrm{n}$ and \% } \\
\hline Daily & 23 & 10.0 & 72,414 & 13.0 \\
\hline 4-6 times a week & 12 & 5.2 & 32,097 & 5.8 \\
\hline $2-3$ times a week & 27 & 11.7 & 45,353 & 8.1 \\
\hline Once a week & 14 & 6.1 & 18,529 & 3.3 \\
\hline $2-3$ times a month & 22 & 9.6 & 37,327 & 6.7 \\
\hline Once a month or less often & 47 & 20.4 & 136,676 & 24.6 \\
\hline I do not drink alcohol & 85 & 37.0 & 214,097 & 38.5 \\
\hline Currently exercise, $\mathrm{n}$ and $\%$ & 138 & 60.0 & 342,821 & 61.6 \\
\hline Frailty, $\mathrm{n}$ and $\%$ & 62 & 27.0 & 172,615 & 31.0 \\
\hline
\end{tabular}

Note: Income values are in USD.

Abbreviations: BMI, body mass index; M, mean; SD, standard deviation.

average age of 74.8 years, two-third of them were female $(64.6 \%)$, the patients were predominantly White/Caucasian (97.4\%), about half were married (55.2\%), and about one quarter were widowed (23.6\%). With regard to education and income, a slight majority had a college education or higher $(56.9 \%)$ and annual incomes of less than $\$ 50,000$ (51.4\%). With regard to health behaviors, a majority of patients in this group were overweight $(27.3 \%)$ or obese $(40.3 \%)$, had never smoked cigarettes $(54.5 \%)$, drank alcohol once a month or less often or not at all (63.1\%), and reported that they used to exercise (61.6\%). Finally, roughly one third (31.0\%) reported the use of medical assistance devices and/or medical conditions that would categorize them as "frail" according to our definition (see the "Methods" section).

\section{Reasons for stopping AC therapy}

In total, 79 patients indicated that they had been previously prescribed an AC, but that they had stopped taking the AC. The frequencies of the factors for stopping $\mathrm{AC}$ therapy are provided in Table 2.

Among those who had been prescribed an AC previously but had stopped taking it, the order of reasons from
Table 2 Which of the following are reasons why you stopped taking an $\mathrm{AC}$ to treat your AF?

\begin{tabular}{lll}
\hline Factor & Patients (\%) & Patients (n) \\
\hline Bleeding concern & 27.8 & 22 \\
Medical & 26.6 & 21 \\
Patient beliefs and preferences & 21.5 & 17 \\
Self-efficacy & 13.9 & 11 \\
Cost & 7.6 & 6 \\
\hline
\end{tabular}

Notes: $\mathrm{N}=79$ former $\mathrm{AC}$ users. Factors listed in order of most to least common. Abbreviations: $A C$, anticoagulant; $A F$, atrial fibrillation.

most commonly selected to least selected by factor (for specific items that comprise each factor, see Figure S1) was: bleeding concern (27.8\%), medical (26.6\%), patient beliefs and preferences (21.5\%), self-efficacy (13.9\%), and cost $(7.6 \%)$. It should be noted that the chief concern, "bleeding" (27.8\%) was the chief concern among patients in this analysis sample who were selected for analyses because their ATRIA scores identify them as "low risk" of bleed. Thus, these patients' primary concerns were with a problem for which at least one diagnostic tool identified them as being at low risk.

\section{Reasons for never starting AC therapy (not filling a prescription)}

A small number $(n=9)$ of patients indicated that they had been prescribed an AC but they had never filled the prescription. The three most common reasons selected by these patients for not filling the prescription were all bleeding and injuryrelated concerns ("I had concern with the risk of bleeding internally or because of injuries", "I had prior hemorrhages or other bleeding events which made me concerned about taking an anticoagulant", and "I had concerns about falling down and how injuries could be worse if I am on an anticoagulant"). Because of the small sample size, these questions were not analyzed further.

\section{Reasons for never being prescribed AC therapy}

In total, 147 patients indicated that they had never been prescribed an AC. The frequencies of each factor are provided in Table 3.

Table 3 Why weren't you prescribed an anticoagulant (eg, warfarin) to treat your AF?

\begin{tabular}{lll}
\hline Factor & Patients (\%) & Patients (n) \\
\hline Antiplatelets & 57.1 & 84 \\
Stroke risk & 17.7 & 26 \\
Other & 4.8 & 7 \\
Physician order & 1.4 & 2 \\
\hline
\end{tabular}

Notes: $\mathrm{N}=147$. Patients advised to select all factors that apply. Factors listed in order of most to least common responses.

Abbreviation: AF, atrial fibrillation. 
Table 4 Patient preference factors associated with anticoagulant treatment

\begin{tabular}{lll}
\hline Factor & M & SD \\
\hline Authority & 5.07 & 0.98 \\
Cost concerns/patient preferences & 4.13 & 1.01 \\
Medication cautiousness & 3.77 & 1.07 \\
\hline
\end{tabular}

Note: All items were answered on a seven point Likert-type scale where I= "strongly disagree" and 7= "strongly agree".

Abbreviations: M, mean; SD, standard deviation.

Among those patients who were not prescribed an AC $(n=147)$, the order of reasons from most selected to least selected by factor (for specific items that comprise each factor, see Table 3) was: antiplatelets (57.1\%), stroke risk $(17.7 \%)$, other (4.8\%), and physician order (1.4\%). Notably, these patients overwhelmingly chose antiplatelet therapy as a reason for not using $\mathrm{AC}(57.1 \%)$ rather than stroke risk, despite the fact that these patients were identified by the $\mathrm{CHA}_{2} \mathrm{DS}_{2}$-VASc as "high risk" of stroke. Therefore, they may not be accurately estimating their risk for such an outcome.

\section{Patient preferences}

All patients, regardless of whether they were currently treated with an $\mathrm{AC}$, were asked to provide their preferences with regard to the features of $\mathrm{AC}$ treatment, using a seven-point Likert scale. Average patient agreement with each domain is presented in Table 4. As can be seen in the table, patients most strongly agreed with items associated with authority (Mean $=5.07, \mathrm{SD}=0.98$ ), followed by items associated with cost concerns/patient preferences (Mean $=4.13, \mathrm{SD}=1.01$ ) and medication cautiousness (Mean $=3.77, \mathrm{SD}=1.07$ ).

\section{Willingness to adhere to different dosing regimens}

Finally, patients were asked six questions about treatment convenience and regimen using a five-point Likert scale. Mean and SD for these items are provided in Table 5. Patients rated taking a pill once a day more favorable (Mean $=3.98$,

Table 5 Attitudes toward anticoagulant treatment

\begin{tabular}{lll}
\hline Item & M & SD \\
\hline Taking a pill once a day with a meal, such as dinner & 3.98 & 0.85 \\
Taking a pill twice a day with or without a meal & 3.59 & 1.04 \\
Taking a pill that requires frequent follow-up visits & 2.56 & 1.07 \\
(at least once a month) to a doctor & & \\
Taking a pill that may require dosage changes often & 2.50 & 0.99 \\
Taking a medication that requires that I avoid eating & 2.50 & 1.02 \\
certain foods (such as leafy greens and certain fruits) & & \\
Taking a medication that requires routine & 2.42 & 1.04 \\
monitoring with blood tests once a month & & \\
\hline
\end{tabular}

Notes: I= "not at all willing" and $5=$ "extremely willing"; Items are ranked by willingness, from most willing to least willing.

Abbreviations: M, mean; SD, standard deviation.
$\mathrm{SD}=0.85)$ than taking a pill twice a day $($ Mean $=3.59$, $\mathrm{SD}=1.04)$.

\section{Discussion}

Following recent updates to AF clinical treatment guidelines, we quantified reasons for not receiving $\mathrm{AC}$ treatment and assessed attitudes toward medication use in NVAF patients at high risk of stroke and low risk of bleed who were not currently using an AC therapy. ${ }^{3}$ Patients reported concerns, beliefs, or preference as drivers for stopping AC therapy, while only about a quarter of them had an actual medical rationale. Among patients who never started AC therapy, more than half perceived antiplatelet therapy as sufficient, despite their heightened risk of stroke. Patients indicated that they regard their physicians' recommendation as the most important influence of their decisions, and they preferred a simpler regimen, such as a once-daily therapy.

When our prevalence estimates were weighted to the US adult AF population ( $\mathrm{N}=3,033,901)$, findings suggested that approximately $76.9 \%$ are both at high risk of stroke and low risk of bleed. Thus, use of AC medications may be indicated and efficacious in a large proportion of this patient population. Overall, we found that nearly one-third of NVAF patients at high risk for stroke, but low risk for serious bleeding, were, by self-report, either never prescribed an AC medication or had been prescribed the medication but were not currently taking it. This finding is consistent with previous literature reporting AF patients at high risk of stroke to not be receiving $\mathrm{AC}$ therapies. ${ }^{20} \mathrm{We}$ also found that younger patients ( $\leq 64$ years) and older patients ( $\geq 80$ years) were less likely to be receiving AC treatment relative to patients 65-79 years of age.

Patients in the present study commonly referenced medical reasons (eg, being ordered not to take an $\mathrm{AC}$ due to a contraindicated medical condition or had improvement in $\mathrm{AF}$ status such that the AC medication was no longer needed). However, despite being classified as at high risk of stroke and low risk of bleed by this study, many patients endorsed potentially inaccurate beliefs about being at higher risk for bleeding and lower risk for having a stroke than may actually be the case. Many also reported uncertainty regarding the reasons for not having been prescribed an AC. Therefore, one method by which the likelihood of patients receiving appropriate AF treatment could be increased is brief educational strategies. Moreover, patients rated concerns about medication expense and convenience above side effect concerns, suggesting that it is vital to ensure that ACs are reasonably priced and readily available. Our findings are consistent with literature citing medical reasons as common reasons for not initiating, or discontinuing, AC medication use. ${ }^{20}$ However, 
previous studies did not delineate the reasons for nonuse of AC treatments that are related to patient beliefs or knowledge, or degree of medication expense or convenience.

Regarding responses to questions about treatment preferences, patients most frequently agreed with statements indicating a high degree of trust in physicians and other health professionals as experts. Thus, it could be particularly beneficial to have physicians or other health care providers provide brief education interventions, as previously described. One example might be providing patients more information about treatment options. Many patients reported that they had never been prescribed an AC medication, because they had been told that they could manage their AF with ASA, and/or preferred to manage their AF with ASA. However, according to the literature, the degree of benefit, relative to risk, for ASA is debatable. Furthermore, correctly dosed AC medications have been cited as extremely effective in preventing AF-related strokes, with reductions as high as one half compared to ASA. ${ }^{21,22}$ However, the degree to which this applies in the context of the most updated guidelines on when to prescribe AC medications and when to prescribe ASA is somewhat unclear. ${ }^{3}$ Additional work may be needed.

Regarding study limitations, the data analyzed for this report were self-reported rather than extracted from medical charts. Some degree of misclassification of patients, and errors in patient recall, is, therefore, expected. An additional limitation is the use of an opt-in panel as the source of the sample. The sampling strategy for this study was not based on a stratified framework and was instead based on qualification through a screener. Therefore, there is a possibility that some relationships observed within the study or point estimates may not generalize to the general population of AF patients. The rate of $\mathrm{AC}$ undertreatment in the present study sample may be underestimated because, for example, patients willing to answer the series of health-related survey questions asked in this study might already be more likely to attend to their health - and thus more likely to adhere with medical treatment recommendations. If this is the case, our results may actually underestimate the magnitude of the problem. We assessed stroke risk with $\mathrm{CHA}_{2} \mathrm{DS}_{2}$-VASc criteria instead of earlier clinical decision tools (eg, $\mathrm{CHADS}_{2}$ ). In fact, among high-risk AF patients taking $\mathrm{AC}$ medications, $\mathrm{CHA}_{2} \mathrm{DS}_{2}-\mathrm{VASc}$ has been shown to successfully predict cardiovascular events and mortality. With novel AC agents, the $\mathrm{CHA}_{2} \mathrm{DS}_{2}-\mathrm{VASc}$ was thought to be more inclusive, rather than exclusive, of stroke risk factors than other tools. In several independent cohorts, the ability of the $\mathrm{CHA}_{2} \mathrm{DS}_{2}-\mathrm{VASc}$ score to predict or assess the risk of occurrence of stroke or thromboembolism has been compared with that of other tools, and $\mathrm{CHA}_{2} \mathrm{DS}_{2}-\mathrm{VASc}$ consistently better identifies these events in patients at low to moderate risk. ${ }^{23}$ Furthermore, we used the ATRIA in this study, which may have affected the results. Future studies might expand upon this work by using alternative measures of bleeding risk such as the HAS-BLED. Finally, barriers to treatment involve not only the patient, but also the physician and the health system. Given the fact that this study only surveyed patients, it only represents one aspect of this complex picture.

Ultimately, our results suggest that a large proportion of NVAF patients at risk for morbidity could benefit from AC medication regimens, but for many, these regimens are not being used. This was particularly true for patients 65-79 years of age, relative to younger or older patients. In some cases, the nonuse may, in fact, relate to patient attitudes and inaccurate beliefs, or to the expense or inconvenience of taking the medication, instead of medical reasons. Efforts focusing on educational strategies to promote accurate knowledge of $\mathrm{AF}$, its risks, and its treatment by medical professionals, as well as efforts to offset the economic burden and improve availability of ACs are thus recommended.

\section{Acknowledgments}

The authors acknowledge Marco DiBonaventura and Tammy Schuler for their assistance in the review and preparation of this manuscript. Data analyses were funded by Janssen Scientific Affairs.

\section{Author contributions}

All authors contributed toward data analysis, drafting and critically revising the paper, gave final approval of the version to be published, and agree to be accountable for all aspects of the work.

\section{Disclosure}

Concetta Crivera, Winnie W Nelson, and Jeff R Schein are employees of Janssen Scientific Affairs, LLC, the sponsor of this study. Edward A Witt is an employee of Kantar Health. Kantar Health was paid for his consultation on this study by Janssen Scientific Affairs, LLC. The authors report no other conflicts of interest in this work.

\section{References}

1. Camm AJ, Kirchhof P, Lip GY, et al; European Heart Rhythm Association; European Association for Cardio-Thoracic Surgery. Guidelines for the management of atrial fibrillation The Task Force for the management of atrial fibrillation of the European Society of Cardiology (ESC). Eur Heart J. 2010;31(19):2369-2429.

2. Camm AJ, Lip GY, De Caterina R, et al. 2012 Focused Update of the ESC Guidelines for the Management of Atrial Fibrillation: An Update of the 2010 ESC Guidelines for the Management of Atrial Fibrillation. Revista Española de Cardiología (English Edition). 2013;66(1):54. 
3. January C, Wann L, Alpert J, et al; ACC/AHA Task Force Members. AHA/ACC/HRS guideline for the management of patients with atrial fibrillation: a report of the American College of Cardiology/American Heart Association Task Force on practice guidelines and the Heart Rhythm Society. Circulation. 2014;130(23):2071-2104.

4. Peters NS, Schilling RJ, Kanagaratnam P, Markides V. Atrial fibrillation: strategies to control, combat, and cure. Lancet. 2002;359(9306): 593-603.

5. Lip GY, Tse HF. Management of atrial fibrillation. Lancet. 2007; 370(9587):604-618.

6. Carl van Walraven M, Hart RG, Connolly S, et al. Effect of age on stroke prevention therapy in patients with atrial fibrillation. Stroke. 2009; 40(4):1410-1416.

7. Hughes M, Lip G; Guideline Development Group, National Clinical Guideline for Management of Atrial Fibrillation in Primary and Secondary Care, National Institute for Health and Clinical Excellence. Stroke and thromboembolism in atrial fibrillation: a systematic review of stroke risk factors, risk stratification schema and cost effectiveness data. Thromb Haemost. 2008;99(2):295-304.

8. Investigators, $58 \mathrm{AF}$. Echocardiographic predictors of stroke in patients with atrial fibrillation: a prospective study of 1,066 patients from 3 clinical trials. Arch Intern Med. 1998;158(12):1316.

9. Banerjee A, Taillandier S, Olesen JB, et al. Ejection fraction and outcomes in patients with atrial fibrillation and heart failure: the Loire Valley Atrial Fibrillation Project. Eur J Heart Fail. 2012;14(3): 295-301.

10. Go AS, Mozaffarian D, Roger VL, et al; American Heart Association Statistics Committee and Stroke Statistics Subcommittee. Heart disease and stroke statistics - 2014 update: a report from the American Heart Association. Circulation. 2014;129(3):399-410.

11. Miyasaka Y, Barnes ME, Gersh BJ, et al. Secular trends in incidence of atrial fibrillation in Olmsted County, Minnesota, 1980 to 2000, and implications on the projections for future prevalence. Circulation. 2006;114(2):119-125.

12. Gage BF, Waterman AD, Shannon W, Boechler M, Rich MW, Radford MJ. Validation of clinical classification schemes for predicting stroke: results from the National Registry of Atrial Fibrillation. JAMA. 2001;285(22):2864-2870.
13. Lip GY, Nieuwlaat R, Pisters R, Lane DA, Crijns HJ. Refining clinical risk stratification for predicting stroke and thromboembolism in atrial fibrillation using a novel risk factor-based approach: the euro heart survey on atrial fibrillation. Chest. 2010;137(2):263-272.

14. Brown TM, Siu K, Walker D, Pladevall-Vila M, Sander S, Mordin M. Development of a conceptual model of adherence to oral anticoagulants to reduce risk of stroke in patients with atrial fibrillation. J Manag Care Pharm. 2012;18(5):351-362.

15. Gupta S, Goren A, Freedman D. Risk of stroke and preventative steps among patients diagnosed with atrial fibrillation in Europe. ISPOR 13th Annual European Congress; November 6th-9th, 2010; Prague, Czech Republic.

16. Patel AA, Lennert B, Macomson B, et al. Anticoagulant use for prevention of stroke in a commercial population with atrial fibrillation. $\mathrm{Am}$ Health Drug Benefits. 2012;5(5):291-298.

17. Lang K, Bozkaya D, Patel AA, et al. Anticoagulant use for the prevention of stroke in patients with atrial fibrillation: findings from a multipayer analysis. BMC Health Serv Res. 2014;14(1):329.

18. Fang MC, Go AS, Chang Y, et al. A new risk scheme to predict warfarinassociated hemorrhage. The ATRIA (Anticoagulation and Risk Factors in Atrial Fibrillation) Study. J Am Coll Cardiol. 2011;58(4):395-401.

19. Naccarelli GV, Varker H, Lin J, Schulman KL. Increasing Prevalence of atrial fibrillation and flutter in the United States. Am J Cardiol. 2009;104(11):1534-1539.

20. Semchuk WM, Levac B, Lara M, Shakespeare A, Evers T, Bolt J. Management of stroke prevention in Canadian patients with atrial fibrillation at moderate to high risk of stroke. Can J Hosp Pharm. 2013;66(5):296.

21. Patrono C, Andreotti F. Antithrombotic therapy for patients with atrial fibrillation and atherothrombotic vascular disease: striking the right balance between efficacy and safety. Circulation. 2013;128(7):684-686.

22. Heidbuchel H, Verhamme P, Alings M, et al; European Heart Rhythm Association. European Heart Rhythm Association Practical Guide on the use of new oral anticoagulants in patients with non-valvular atrial fibrillation. Europace. 2013;15(5):625-651.

23. Jover E, Roldán V, Gallego $\mathrm{P}$, et al. Predictive value of the $\mathrm{CHA}_{2} \mathrm{DS}_{2}-$ VASc score in atrial fibrillation patients at high risk for stroke despite oral anticoagulation. Revista Española de Cardiología (English Edition). 2012;65(7):627-633. 


\section{Supplementary materials}

Which of the following are reasons why you stopped taking an anticoagulant to treat your atrial fibrillation? (Select all that apply)

Cost

- I could not afford the prescription medication

- I could not afford co-pay to see a specialist

- I do not have health insurance coverage anymore

- I decided to make lifestyle changes, so I did not need to be on an anticoagulant

Patient beliefs and preferences

- I do not believe I am at a high risk of stroke

- I do not believe I need to be on an anticoagulant

- I decided I did not want to be on anticoagulant therapy

Self-efficacy

- I had concerns about following the medication instructions

- I had concerns about my ability to take pills as directed

- I had difficulty with making other necessary lifestyle changes when on anticoagulant (eg, diet/exercise)

- I had to take blood tests to check my INR (International Normalized Ratio) values too frequently, so I decided to stop taking my anticoagulant

- I do not know what anticoagulants do, so I did not feel comfortable taking it

Medical

- I injured myself and my doctor told me to stop taking the anticoagulant

- I was undergoing surgery and was instructed to stop taking the anticoagulant by a medical professional

- My physician was not happy with my INR (international normalized ratio) lab values (from blood tests) and took me off my anticoagulant

- I have other medical conditions that would not allow for anticoagulants to be used

- I was already receiving antiplatelet therapy (eg, Plavix)

Bleeding concern

- I had concerns about the risk of bleeding (internally or because of injuries)

- I had prior hemorrhages or other bleeding events which made me concerned about taking an anticoagulant

- I had concern about falling down and how injuries could be worse if I am on an anticoagulant

- I feel I am taking too many prescription medications already

- My lifestyle is too active to participate in risky activities which put me at risk for bleeding

Figure SI Reasons for stopping taking an anticoagulant (asked of previous anticoagulant users). 
Why did you not fill the anticoagulant prescription your physician recommended?

- I had concerns about following the medications instructions

- I had concerns about my ability to take pills as directed

- I had difficulty with making other necessary lifestyle changes needed when on anticoagulant (eg, diet/exercise)

- I had concern with the risk of bleeding (internally or because of injuries)

- I had prior hemorrhages or other bleeding events which made me concerned about taking an anticoagulant

- I injured myself and did not want to take an anticoagulant

- I was undergoing surgery and did not want to start the prescription

- I had concerns about falling down and how injuries could be worse if I am on an anticoagulant

- I do not believe I am at a high risk of stroke

- I do not believe I need to be on an anticoagulant

- I feel there would be too many follow-up doctor visits to do blood tests

- I have other medical conditions that would not allow for anticoagulants to be used

- I am taking too many prescription medications already

- My atrial fibrillation status changed, and an anticoagulant was no longer needed

- I decided I did not want to be on anticoagulant therapy

- I could not afford the prescription medication

- I could not afford co-pay to see a specialist

- My lifestyle is too active to participate in risky activities which put me at risk for bleeding

- I do not have health insurance coverage anymore

- I decided to make lifestyle changes, so I didn't need to be on an anticoagulant

- I was diagnosed at an emergency room and was not given any prescriptions to fill/to take following my discharge

- I do not know what anticoagulants do, so I did not feel comfortable taking it

Figure S2 Atrial fibrillation treatment (asked of those who were prescribed an anticoagulant but did not fill the prescription).

Why weren't you prescribed an anticoagulant (eg, warfarin) to treat your atrial fibrillation (AF)?

Physician order

- My doctor felt that the anticoagulant treatment regimen (number of pills, tests needed, office visits needed) was too difficult for me to follow

- Due to my risk for injuries from activities (social or job related), my doctor suggested that I not treat my AF with an anticoagulant Stroke risk

- My doctor told me that my risk for stroke is low

- I believe that I do not have a high risk for stroke

Antiplatelets

- I am taking an antiplatelet therapy (eg, Plavix)

- My physician said I can just take aspirin to control my AF

- I prefer to just take aspirin

Other

- I never saw a physician to treat my AF

- I was diagnosed at an emergency room and was not given any prescriptions to fill/to take following my discharge

Figure S3 Atrial fibrillation treatment (asked of those who were never prescribed an anticoagulant). 
Please read each of the following statements and indicate on the scale below how much you agree with each statement. (Select one response for each row)

\begin{tabular}{|c|c|c|c|c|c|c|}
\hline Strongly disagree & Disagree & Somewhat disagree & Neither agree nor disagree & Somewhat agree & Agree & Strongly agree \\
\hline 1 & 2 & 3 & 4 & 5 & 6 & 7 \\
\hline
\end{tabular}

\section{Authority}

- I'm willing to take an additional medication if my doctor says I need it to prevent heart attack or stroke

- I am willing to take steps to simplify my medication regimen by speaking to my physician or pharmacist

- My doctor is the expert and if he/she recommends a specific prescription treatment, I will faithfully follow their instructions

- I do not mind going to doctors' offices, so taking a medication that requires frequent monitoring by my physician works fine for me

Cost concerns/patient preference

- I prefer that my health care provider prescribes the least expensive drugs for me

- Sometimes I do not fill or refill prescriptions because I need to pay for other necessities

- I would prefer to take one pill once a day instead of taking one pill twice a day

- I prefer to be on medications that do not make me change my lifestyle (ie, diet or exercise changes) even if there is a more effective treatment

\section{Medication cautiousness}

- I prefer to take alternative medicines and treatments (eg, herbal medicine, supplements, acupuncture, etc) instead of prescription medications

- It is more important to me for a medication to have fewer or no side effects, even if my doctor says it is less effective

- I always look to get a second opinion from another health care provider before I make a decision about going on a prescription medication

Figure S4 Patient preferences for anticoagulant treatment.

Below is a list of statements related to the treatment for your atrial fibrillation. On the scale below, please indicate your level of willingness to take each described treatment. (Select one response per row)

\begin{tabular}{lllll}
\hline Not at all willing & Not very willing & Somewhat willing & Very willing & Extremely willing \\
\cline { 2 - 3 } & 2 & 3 & 4 & 5 \\
\hline
\end{tabular}

- Taking a pill once a day with a meal, such as dinner

- Taking a pill twice a day with or without a meal

- Taking a pill that may require dosage changes often

- Taking a pill that requires frequent follow-up visits (at least once a month) to a doctor

- Taking a medication that requires that I avoid eating certain foods (such as leafy greens and certain fruits)

- Taking a medication that requires routine monitoring with blood tests once a month

Figure S5 Patient dosing regimen characteristics.

Patient Preference and Adherence

\section{Publish your work in this journal}

Patient Preference and Adherence is an international, peer-reviewed, open access journal that focuses on the growing importance of patient preference and adherence throughout the therapeutic continuum. Patient satisfaction, acceptability, quality of life, compliance, persistence and their role in developing new therapeutic modalities and compounds to optimize

\section{Dovepress}

clinical outcomes for existing disease states are major areas of interest for the journal. This journal has been accepted for indexing on PubMed Central. The manuscript management system is completely online and includes a very quick and fair peer-review system, which is all easy to use. Visit http://www. dovepress.com/testimonials.php to read real quotes from published authors. 